\title{
Urinary Bladder Detrusor Dysfunction Symptoms in Lyme Disease
}

\author{
Basant K. Puri ${ }^{1}$, Mussadiq Shah ${ }^{2}$, Peter O. Julu ${ }^{1,2,3}$, Michele C. Kingston ${ }^{2}$, Jean A. Monro ${ }^{2}$ \\ ${ }^{1}$ Department of Medicine, Imperial College London, London, UK; \\ ${ }^{2}$ Department of Neuroscience, Breakspear Medical Group, Hemel Hempstead, UK; \\ ${ }^{3}$ National Rett Center, Frösön, Sweden
}

Purpose: Symptoms of urinary bladder detrusor dysfunction have been rarely reported in Lyme disease. The aim was to carry out the first systematic study to compare the prevalence of such symptoms in a group of Lyme disease patients and a group of matched controls.

Methods: A questionnaire relating to detrusor function was administered to 17 serologically positive Lyme disease patients and to 18 control subjects.

Results: The two groups were matched in respect of age, sex, body mass, and mean arterial blood pressure. None of the 35 subjects was taking medication which might affect urinary function and none had undergone a previous operative procedure on the lower urinary tract. Six of the Lyme patients $(35 \%)$ and none of the controls $(0 \%)$ had symptoms of detrusor dysfunction $(\mathrm{P}<0.01)$.

Conclusions: This first systematic controlled study confirms that Lyme disease is associated with urinary bladder detrusor dysfunction. Further evaluation of detrusor function is warranted in this disease.

Keywords: Bladder function; Lyme disease; Urinary bladder

\section{INTRODUCTION}

Lyme disease or Lyme borreliosis is a systemic arthropod-borne zoonosis caused by Borrelia spirochaetes, the incidence of which has recently been increasing with the geographical spread of infected ticks. It is well established that the bacteria can invade the skin (causing erythema migrans), musculoskeletal system (giving rise to Lyme arthritis), cardiovascular system (causing Lyme carditis), and the nervous system (Lyme neuroborreliosis) [1].

There are rare reports that Lyme disease may also affect the urinary bladder. A study of chronic neurological manifestations of erythema migrans in 44 patients seen between 1985 and 1987 in the Federal Republic of Germany (West Germany) reported that 11 of these patients (25\%) suffered from 'bladder dysfunction'; no further details were given of the symptoms associated with this [2]. In 1990, Chancellor et al. [3] reported a case of Lyme disease presenting with urinary retention; the patient then went on to suffer lower extremity paralysis, and both the urinary retention and the paralysis responded to intravenous ceftriaxone therapy. Three years later, Chancellor et al. [4] described a series of seven patients with neuroborreliosis who also suffered from lower urinary tract dysfunction. Finally, last year Kim et al. [5] reported a case of neurogenic bladder in Lyme neuroborreliosis, which did not respond to intravenous ceftriaxone. These two case reports and two case series were not controlled.

The aim was to carry out the first systematic study to compare the prevalence of symptoms of urinary bladder detrusor dysfunction in a group of Lyme disease patients and a group of matched controls.
Corresponding author: Basant K. Puri

Imaging Directorate, Block A, Level 1, Hammersmith Hospital, Du Cane Road, London W12 0HS, UK

Tel: +44-1442-261-333 (ext. 314) / Fax: +44-1442-266-388

E-mail: basant.puri@imperial.ac.uk

Submitted: September 7, 2013 / Accepted after revision: September 12, 2013
This is an Open Access article distributed under the terms of the Creative Commons Attribution Non-Commercial License (http://creativecommons.org/licenses/by-nc/3.0/) which permits unrestricted non-commercial use, distribution, and reproduction in any medium, provided the original work is properly cited. 
Table 1. Bladder control - detrusor function questions

1. Do you feel your bladder is empty after you have passed urine?

2. Do you have difficulty starting to pass urine?

3. Can you pass or hold urine when you want to?

4. How often do you empty your bladder during the daytime?

5. How often do you empty your bladder at night?

\section{MATERIALS AND METHODS}

\section{Subjects}

This study was cross-sectional and carried out in the Breakspear neuroscience department. Serologically positive Lyme disease patients who were undergoing routine clinical investigations and normal controls were assessed with respect to medication, past medical history, body mass, and arterial blood pressure. Exclusion criteria included: taking medication which could affect urinary bladder function, such as diuretics, calcium channel blockers, alpha-adrenergic antagonists, antipsychotics, tricyclic antidepressants, selective serotonin re-uptake inhibitors, muscle relaxants, opioids and theophylline; a history of past operative procedures on the lower urinary tract, including sphincterotomy, transurethral resection of the prostate and urethropexy; and a history of spinal or pelvic operations which might affect bladder function.

Written informed consent was obtained and a Research Ethics Committee approved the study, which was carried out in accordance with the Declaration of Helsinki.

\section{Assessment of Detrusor Dysfunction Symptoms}

Detrusor function was assessed by asking all subjects the questions shown in Table 1. An affirmative answer to the first three questions or an answer to the fifth answer consistent with nocturia was taken as symptomatic of detrusor dysfunction.

\section{Statistical Analysis}

Continuous variables for which data which did not differ significantly from normality and for which the two groups did not have significantly different variances were compared between the Lyme disease and control groups using independent samples t-tests (equal variances), while the discrete nominal variables were compared between groups using Fisher exact probability test. All tests were two-tailed. The software package IBM SPSS ver. 20.0 (IBM Co., Armonk, NY, USA) was used for the statistical analyses.
Table 2. The mean age, sex ratio, mean body mass, and mean arterial blood pressure for each group

\begin{tabular}{lccc} 
Variable & $\begin{array}{c}\text { Lyme disease } \\
(\mathrm{n}=17)\end{array}$ & $\begin{array}{c}\text { Controls } \\
(\mathrm{n}=18)\end{array}$ & P-value \\
\hline Age $(\mathrm{yr})$ & $36.2(3.9)$ & $44.7(3.9)$ & 0.132 \\
Sex & & & 1.000 \\
$\quad$ Male & 6 & 7 & \\
$\quad$ Female & 11 & 11 & \\
$\begin{array}{l}\text { Body mass (kg) } \\
\begin{array}{l}\text { Arterial blood pressure } \\
(\mathrm{mmHg})\end{array}\end{array}$ & $24.7(1.3)$ & $24.6(0.8)$ & 0.937 \\
\hline
\end{tabular}

Values are presented as mean (standard error).

\section{RESULTS}

Seventeen serologically positive Lyme disease patients and 18 control subjects were studied. The mean age, sex ratio, mean body mass, and mean arterial blood pressure for each group are shown in Table 2, from which it can be seen that the two groups were matched in respect of all these parameters.

Six of the Lyme disease group (35\%) had symptoms of detrusor dysfunction compared with none $(0 \%)$ of the controls (Fisher exact probability test, $\mathrm{P}=0.008$ ).

\section{DISCUSSION}

This first systematic controlled study confirms that Lyme disease is associated with urinary bladder detrusor dysfunction. That the prevalence in the present study was over a third indicates that it is important that urological complications of Lyme disease be checked for in patients with this infection.

Further urological studies in Lyme disease are warranted, including assessment of the prevalence of detrusor dysfunction in larger sample sizes and laboratory evaluation of urinary bladder function by urodynamic studies. Studies also need to be carried out to evaluate the response to antibiotic therapy.

\section{CONFLICT OF INTEREST}

No potential conflict of interest relevant to this article was reported.

\section{REFERENCES}

1. Biesiada G, Czepiel J, Leśniak MR, Garlicki A, Mach T. Lyme dis- 
ease: review. Arch Med Sci 2012;8:978-82.

2. Ackermann R, Rehse-Kupper B, Gollmer E, Schmidt R. Chronic neurologic manifestations of erythema migrans borreliosis. Ann N Y Acad Sci 1988;539:16-23.

3. Chancellor MB, Dato VM, Yang JY. Lyme disease presenting as urinary retention. J Urol 1990;143:1223-4.

4. Chancellor MB, McGinnis DE, Shenot PJ, Kiilholma P, Hirsch IH. Urinary dysfunction in Lyme disease. J Urol 1993;149:26-30.

5. Kim MH, Kim WC, Park DS. Neurogenic bladder in lyme disease. Int Neurourol J 2012;16:201-4. 